\title{
Yeraltı Kablosuz Algılayıcı Ağlar için Bulanık Mantık Tabanlı Toplayıcı İstasyon Karar Yaklaşımı
}

\author{
Fuzzy Logic Based Collector Station Decision Approach for Underground Wireless Sensor \\ Networks
}

Muhammed Enes BAYRAKDAR*

Düzce Üniversitesi, Teknoloji Fakültesi, Bilgisayar Mühendisliği Bölümü, 81620, Düzce

• Geliş tarihi / Received: 02.04.2019 • Düzeltilerek geliş tarihi / Received in revised form: 28.08.2019 • Kabul tarihi / Accepted: 09.09.2019

\begin{abstract}
$\ddot{\mathbf{O} z}$
$\mathrm{Bu}$ makale çalışmasında, yeraltı kablosuz algılayıcı ağlarında kayıpsız veri iletimi yapabilmesi için bulanık mantık tabanlı toplayıcı istasyon karar yaklaşımı önerilmiştir. Algılayıcı düğümlerin enerji tasarruflu kayıpsız veri iletimi yapabilmesi için, toplayıcı istasyon karar işlemleri bulanık mantık yardımıyla gerçekleştirilmiştir. Önerilen yeraltı kablosuz algılayıcı ağ yapısının benzetim modeli Riverbed yazılımı kullanılarak gerçekleştirilmiştir. Matlab yazılımı kullanılarak anlık olarak bulanık mantık tabanlı karar işlemi yapılmıştır. Bulanık mantık sisteminde; enerji, derinlik ve kullanım giriş parametreleri değerlendirilerek toplayıcı istasyon kararı çıkış değeri elde edilmektedir. Kablosuz algılayıcı ağlarda sıklıkla kullanılan iş çıkarma başarımı ve enerji tüketimi parametreleri incelenerek, önerilen yeraltı kablosuz algılayıcı ağ performansı değerlendirilmiştir. Önerilen algılayıcı ağ performansını değerlendirmek için sonuçlara bakıldığında, maksimum iş çıkarma başarım oranı ve ortalama enerji tüketimi ile yeraltı kablosuz algılayıcı ağlarda kayıpsız veri iletimi yapıldığı gözler önüne serilmiştir. Önerilen bulanık mantık sistemi sayesinde; kablosuz algılayıcı ağlar için en uygun toplayıcı istasyon seçimi yapılmakta ve enerji tüketimi mümkün olan en düşük seviyede tutulmaktadır.
\end{abstract}

Anahtar kelimeler: Bulanık mantık, kablosuz algılayıcı ağ, toplayıcı istasyon, yeraltı

\begin{abstract}
In this paper, fuzzy logic based collector station decision approach is proposed in order to provide lossless data transmission in underground wireless sensor networks. With the aim of allowing the sensor nodes to transmit energyefficient lossless data, the decision of the collector station is performed with the help of fuzzy logic. The simulation model of the proposed underground wireless sensor network was performed using Riverbed software. Fuzzy logicbased decision processing was performed by using Matlab software. In the fuzzy logic system; collector station decision output value is obtained by evaluating energy, depth and usage input parameters. The proposed underground wireless sensor network performance is evaluated by examining the throughput and energy consumption parameters which are commonly used in wireless sensor networks. When the results are examined to evaluate the proposed sensor network performance, it is revealed that lossless data transmission is performed in underground wireless sensor networks with maximum throughput performance and average energy consumption. Thanks to the proposed fuzzy logic system; the most suitable collector station is selected for wireless sensor networks and energy consumption is kept at the lowest possible level.
\end{abstract}

Keywords: Fuzzy logic, wireless sensor network, collector station, underground

*Muhammed Enes BAYRAKDAR; muhammedbayrakdar@ duzce.edu.tr; Tel: (0380) 54211 33; orcid.org/ 0000-0001-9446-0988 


\section{Giriş}

İletişim tekniklerindeki son gelişmelerin yanı sıra, yeraltı ortamdaki algılayıcı a $\breve{g}$ uygulamaları da önemli ölçüde artmıștır. Kablosuz yeraltı algılayıcı ağlar, yeraltı kablosuz algılayıcılardan oluşan ve gelecek vaat eden bir çalışma alanıdır. Kablosuz olması sayesinde, kablolu yeraltı izleme teknikleriyle mümkün olmayan birçok farkl1 uygulamayı yapabilmemize olanak sağlamaktadır. Kablosuz yeraltı algılayıcı ağlar; toprak kayması tahmini, sınır devriyesi, güvenlik, altyapı izleme, toprak durumu izleme, deprem tahmini vb. konularını kapsamaktadır. Ancak; yeraltı iletişimin en zorlu kısmı, katı bir ortam olan yayılma ortamıdır. Bunun ana nedeni, yayılma ortamının hava olduğu karasal kablosuz algılayıc1 ağların aksine yayılım ortamının katı bir ortam toprak vb. olmasıdır. Geleneksel karasal kablosuz algılayıcı ağ teknikleri yeraltı toprak ortamında iyi çalışmadığından, yeni yaklaşımlara ihtiyaç duyulmaktadır.

Literatürde kablosuz yeraltı algılayıc1 ağları hakkında çeşitli çalışmalar bulunmaktadır. Son zamanlarda yapılan çalışmalar enerji verimliliği ve toplayıcı istasyon seçim teknikleri üzerine odaklanmaktadır. Ichihashi ve arkadaşları, park yerlerinde boşluk / doluluk oranını tespit etmek için ParkLotD adlı kamera tabanlı yeni bir sistem hakkında çalışma yapmışlardır (Ichihashi vd., 2009). Lokshina ve Insinga, yeraltı kömür madeni atmosferlerinin izlenmesi ve kontrol işlemleri sırasında alınan gazın dinamik görüntülerin yorumlanması üzerine bir çalışma yapmışlardır. Ayrıca görüntünün işlenmesi için uygulanan bulanık mantık yöntemlerine dayanan bir karar destek sistemi oluşturmuşlardır (Lokshina vd., 2003). Fischer ve arkadaşları, yeraltı elektrik kablolarında kaçak detektörünün uygulanması sirasında göz önünde bulundurulması gereken sorunlar hakkında genel bilgiler vermişlerdir (Fischer vd., 2004). Xianmin ve Lan, çoklu algılayıcı veri füzyon teorisine dayanan elektrikli kömür kırıcısı için yeni bir gerçek zamanlı kömür nakliye izleme sistemi önermişlerdir (Xianmin vd., 2014). Ichihashi ve arkadaşları, bulanık mantık kümelemesi, parçacık sürüsü optimizasyonu ve hiper parametre ayarına dayanan detektör performans1 hakkında bir çalışma yapmışlardır (Ichihashi vd., 2010). Gauss ve Bay, bilinmeyen ortamlarda çalışan bir yeraltı konum keşif robotu için kesin olmayan algılayıcı veriler varlığında bile yörünge belirleyebilen denetimsiz bir bulanık mantık algoritmas1 sunmuşlardır (Gauss ve Bay, 1998). Ahmad ve arkadaşları, tehlikeli operasyonlar sırasında işçilere yönelik izleme işlemini sağlamak için bulanık mantık kullanan ajan tabanlı kişisel bir izleme sistemi önermişlerdir (Ahmad vd., 2011). Zyada ve arkadaşları, insani yardım için bulanık mantık ve algılayıc1 ag tabanlı kurallar sunmuşlardır (Zyada vd., 2006).

Algılayıcı dügümler çok sınırlı bir güce sahip olduklarından, herhangi bir kablosuz algılayıcı ă türünde enerji tüketimini azaltmak önemlidir ( $\mathrm{Ma}$, 2012). Literatürde, bu konu ile ilgili olarak çok fazla araştırma yapılmaya devam etmektedir (Jaryani vd., 2015). Bununla birlikte; bu araştırmaların çoğu yayılma ortamının hava olduğu karasal kablosuz ağlar için yapılmaktadır (Sinha vd., 1999). Fakat yeraltı ortamı karasal ortamdan tamamen farklıdır. Çünkü yayılma ortamı hava değil, katı bir ortam olan topraktır (Sinha vd., 2002). Zayıflama ve yol kaybı değerleri yeraltı ortamda, yerüstü ortama göre çok daha fazla yüksektir. $\mathrm{Bu}$ nedenle, yeraltı iletişimde enerji tüketimini azaltmanın yollarını araştırmak ve bulmak oldukça önemlidir. $\mathrm{Bu}$ şekilde, kablosuz yeraltı algılayıcı ağların ömrünü artırmak mümkün olacaktır. Ek olarak, verilerin güvenilirliği yeraltı iletişimde dikkat gerektiren başka bir önemli özelliktir. Çünkü bit hata oranı yerüstü iletişimden farklı olmaktadır. Günümüzde, kablosuz algılayıcı ağların güvenilirliğini artırmak için yeraltı hata kontrol kodunun kullanımını araştıran birçok çalışma bulunmaktadır (Gupta vd., 2013).

Bununla birlikte, kablosuz yeralt1 algilayıc1 ağların enerji tüketimini azaltmak için gerçekleştirilen sınırlı sayıda çalışma bulunmaktadır. Huang vd. kablosuz yeraltı algılayıcı ağlar için sınırlı enerji kaynağı ve topolojiye bağlı toleransı incelemişlerdir (Huang vd., 2018). Bunun yanında, enerji tasarruflu rastgele ölçeksiz bir topoloji modeli ve ayarlanabilir oran endeksli bir güç ağı topoloji yapıs1 önermişlerdir. Shahooei vd. yeraltı yük taşımacılı̆̆ 1 için uygun bir sistem tasarlamayı hedeflemişlerdir (Shahooei vd., 2019). Ek olarak, yeraltı sisteminin enerji tüketimini en az seviyede tutmayı amaçlamışlardır. Alzoubi vd (2019) yeraltı madenleri için talep üzerine dondurma ilkesini deneysel ve matematiksel model yardımıyla elde etmişlerdir. Ayrıca, enerji tüketimini en az seviyede tutarak kayıssı veri iletimi yapmayı hedeflemişlerdir. Literatürdeki yeraltı algılayıcı ağlar ile ilgili yapılan çalışmalar incelendiğinde, enerji tüketimini en aza indirmek için bulanık mantık kullanan makale bulunmadığ 1 görülmektedir. 
Bu makale çalışmasında, yeraltı algılayıcı ağlarda kayıpsız veri iletimi yapabilmesi için bulanık mantık tabanlı toplayıcı istasyon karar yaklaşımı önerilmiştir. Algılayıcı düğümlerin enerji tasarruflu kayıpsız veri iletimi yapabilmesi için, toplayıcı istasyon karar işlemleri bulanık mantık yardımıyla gerçekleştirilmiştir. Önerilen yeraltı kablosuz algılayıcı ağ yapısının benzetim modeli Riverbed yazılımı kullanılarak gerçekleştirilmiştir. Matlab yazılımı kullanılarak anlık olarak bulanık mantık tabanlı karar işlemi yapılmıştır.

\section{Bulanık Mantık tabanlı Yeraltı Kablosuz Algılayıcı A $\breve{g}$ Yaklaşımı}

$\mathrm{Bu}$ makale çalışmasında, yeraltındaki konumlarından dolayı yeniden enerji depolanması mümkün olmayan yeraltı algılayıcı düğümler ele alınmıştır. Kablosuz yeraltı algılayıcı düğümlerin yeraltt-yeraltı haberleşme gerçekleştirebilmesi için kablosuz yeraltı algılayıcı ağ tasarımı ve benzetimi yapılmıştır. Kablosuz yeraltı algılayıcı düğümler, toplayıcı istasyona veri aktarmak için yeralt1-yerüstü haberleşme gerçekleştirmektedirler. Enerji verimliliği sağlamak için, yeraltı algılayıcı düğümler, verilerini kendilerine en yakın olan toplayıcı istasyona iletmektedirler. Sezilen verilerin doğrudan toplayıcı istasyona aktarılması mümkün değilse, veriler dolaylı bir şekilde diğer yeraltı algılayıcı düğümleri aracıllğıyla da toplayıcı istasyona iletilebilmektedir.

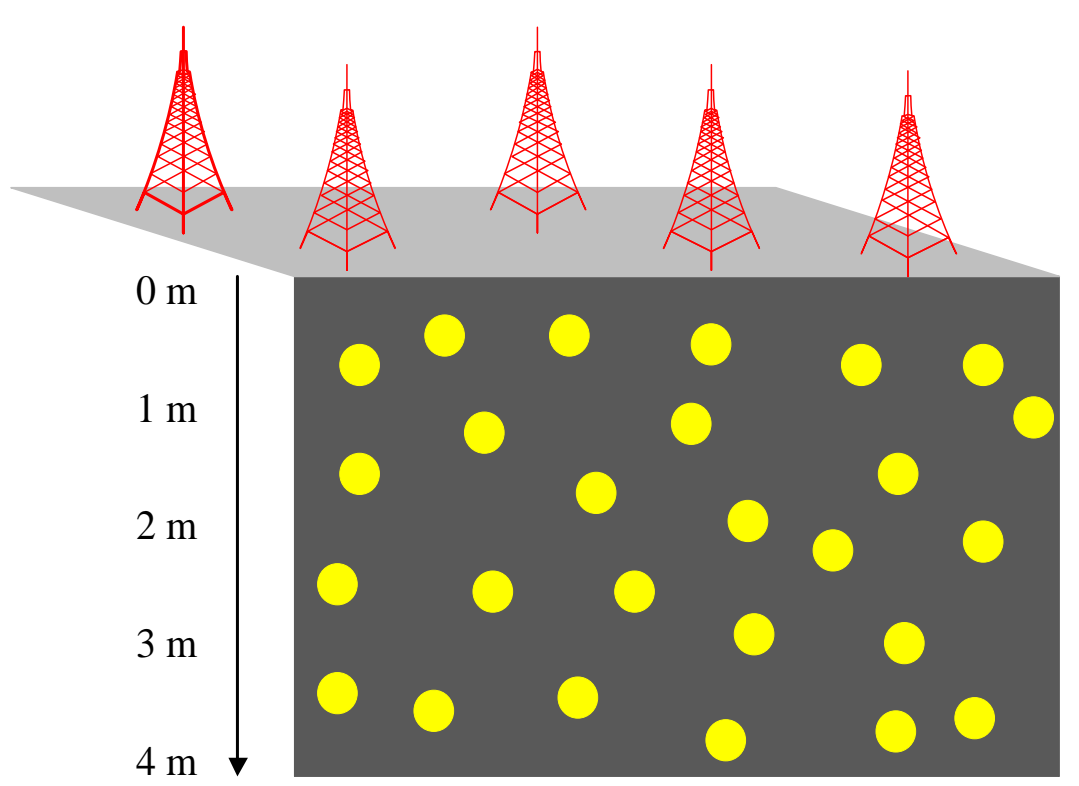

Şekil 1. Kablosuz yeraltı algılayıcı ăg ortamı

Şekil 1'de, önerilen kablosuz yeraltı algılayıc1 ağdaki kablosuz yeraltı algılayıcı düğümler ve toplayıc1 istasyonlar görülmektedir. Kablosuz yeraltı algılayıc1 düğümlerinin görevi veri toplamaktır. Yüzeye yakın olan yeraltı algılayıc1 dügümler; veri toplama işlemine ek olarak, derin yeraltı algılayıcı dügümlerin toplayıcı istasyonlara veri iletme işlemine yardım etmektedirler. Toplayıcı istasyonların görevi, kendisine gelen sezilen verileri toplamaktır. Toplanan veriler herhangi bir çevrimiçi cihazdan izlenebilmektedir. Kablosuz yeraltı algılayıcı dügümler, herhangi bir veri sezme veya gönderme olmadığında boşta beklemektedirler. $\mathrm{Bu}$ durumda, kablosuz yeralt1 algılayıcı düğümler uyku durumuna geçerek mümkün olan en düşük enerji tüketimini sağlamaktadırlar. Kablosuz yeraltı algılayıcı düğümler maksimum 4 metre derinliğe yerleştirilmektedir (Gupta vd., 2013). Sağlıklı bir kablosuz haberleşme, 5 metre derinlikten sonra oldukça azaldığı için benzetim modelinde maksimum derinlik 4 metre olarak ele alınmıştır (Fischer vd., 2004).

Tablo 1. Algılayıcı ağ için kullanılan benzetim parametreleri

\begin{tabular}{|c|c|}
\hline Parametre & Değer \\
\hline Veri oranı & $10 \mathrm{kbps}$ \\
\hline Modülasyon tekniği & Bpsk \\
\hline Algılayıcı düğüm sayısı & 26 \\
\hline Toplayıcı istasyon sayısı & 5 \\
\hline Gönderme gücü & $800 \mathrm{mw}$ \\
\hline Veri paketi boyutu & $40 \mathrm{byte}$ \\
\hline İletim frekansı & $350 \mathrm{MHz}$ \\
\hline Maksimum derinlik & $4 \mathrm{~m}$ \\
\hline
\end{tabular}


Tablo 1'de, yeraltı algılayıcı ağın benzetim parametreleri ve değerleri gösterilmektedir. Veri oran $10 \mathrm{kbps}$ ve modülasyon tekniği bpsk olarak ayarlanmıştır. Buna göre, kablosuz algilayıcı düğüm sayısı 26 ve toplayıc1 istasyon sayıs1 5 olarak seçilmiștir. Gönderme gücü, maksimum derinlikte olan algılayıcı düğüm dikkate alınarak seçildiği için $800 \mathrm{mw}$ olarak belirlenmiştir. Sezilen veriler için kullanılan veri paketi boyutu 40 bayt olarak ele alınmıștır. İletim frekansı olarak, kablosuz yeraltı dügüm haberleşmesi için uygun olan $350 \mathrm{MHz}$ ayarlanmıştır.

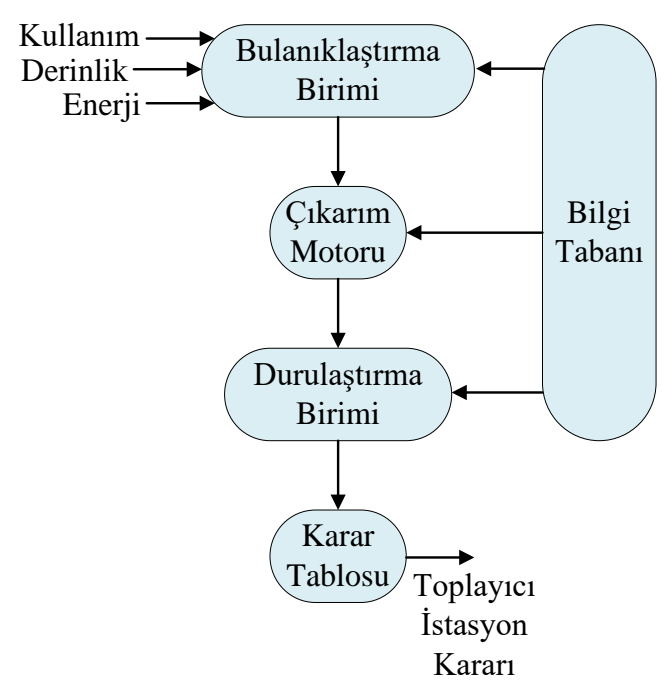

Şekil 2. Önerilen algılayıcı ağın bulanık mantık blok diyagramı

Şekil 2'de, önerilen kablosuz yeraltı algılayıcı ağ için bulanık mantık sisteminin blok diyagramı verilmiştir. Önerilen bulanık mantık sisteminde, kablosuz haberleşme alanındaki çalışmalarda yaygin olarak tercih edilen Mamdani metodu kullanılmıştır (Muduli vd., 2018). Bulanık mantık sistemi; bulanıklaştırma birimi, çıkarım motoru ve durulaştırma birimlerinden oluşmaktadır. Bulanıklaştırma birimi kesin olan net bir girişi bulanık bir değere dönüştürürken, durulaştırma birimi çıkış değerleri setini kesin olan tek bir net değere dönüştürmektedir. Durulaştırma birimi temel olarak, kural tabanlı çıkarım mekanizmasından gelen bulanık ifadeleri sisteme uygulanabilecek sayısal ifadelere dönüştürmektedir. Bu üç birim sürekli olarak bilgi tabanı ile iletişim halinde olmaktadır. Bilgi tabanı, kural tabanı ve üyelik fonksiyonlarından oluşmaktadır. Bulanıklaştırma biriminde, belirli değerler bulanı veri kümelerine dönüştürülmektedir. Bu bulanık kümeler çıkarım motorunda işlendikten sonra, durulaştırma birimi bunları sayısal değerlere dönüştürmektedir. Durulaştırma biriminden sonra, son bir aşama olarak karar tablosu bulunmaktadır. Karar tablosu biriminde, durulaştırma biriminden gelen sayısal değerlere göre toplayıcı istasyon kararı verilmektedir. Çıkış değeri olan toplayıcı istasyon kararı; kullanım, derinlik ve enerji giriş değerleri kullanılarak elde edilmektedir. Üyelik fonksiyonları için üç giriş parametresi ve bu üyelik fonksiyonları için üç farklı seviye bulunmaktadır.

Şekil 3'te, bir yeraltı algılayıc1 düğümün kullanımı için üyelik fonksiyonları gösterilmektedir. Algılayıc1 kullanımı, bir düğümün sezdiği veri trafiği olarak tanımlanmaktadır. Dügüumlerin kullanımı \%0 ile $\% 100$ arasında değişmektedir. Az, orta ve çok olmak üzere 3 seviye bulunmaktadır.

Şekil 4'te bir yeraltı algılayıcı dügümün derinliği için üyelik fonksiyonları gösterilmektedir. Dügümmlerin derinliği 0 metre ile 4 metre arasında değişmektedir. Az, orta ve çok olmak üzere 3 seviye bulunmaktadır. Derinlik, toplayıc1 istasyonu kararı için en etkili parametredir.

Şekil 5'te bir yeraltı algılayıcı dügümünün kalan enerjisi için üyelik fonksiyonları gösterilmektedir. Dügümlerinin kalan enerjisi, 0 joule ve 8 joule arasında değişmektedir. Düşük, orta ve yüksek olmak üzere 3 seviye bulunmaktadır.

Şekil 6'da toplayıcı istasyon kararı için üyelik fonksiyonları görülmektedir. Çıkış olarak, toplayıcı istasyonun çok yakın, yakın veya uzak olması gerektiği sonucuna ulaşılmaktadır. Toplayıcı istasyon kararının çok yakın olması düşük enerji tüketimi avantaji sağlamaktadır. Fakat tüm algılayıcı düğümlerin en yakın toplayıcı istasyon ile haberleşme yapmak istemesi sonucunda, veri trafiği yoğunluğundan dolayı çarpışmalar ve gecikmeler meydana gelebilmektedir.

Tablo 2'de, toplamda 27 kuraldan oluşan kural tablosundaki tüm kurallar görülmektedir.

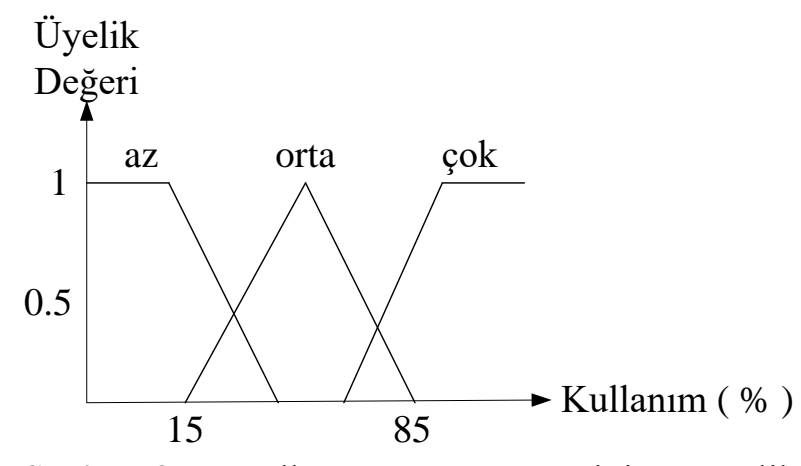

Şekil 3. Kullanım parametresinin üyelik fonksiyonları 


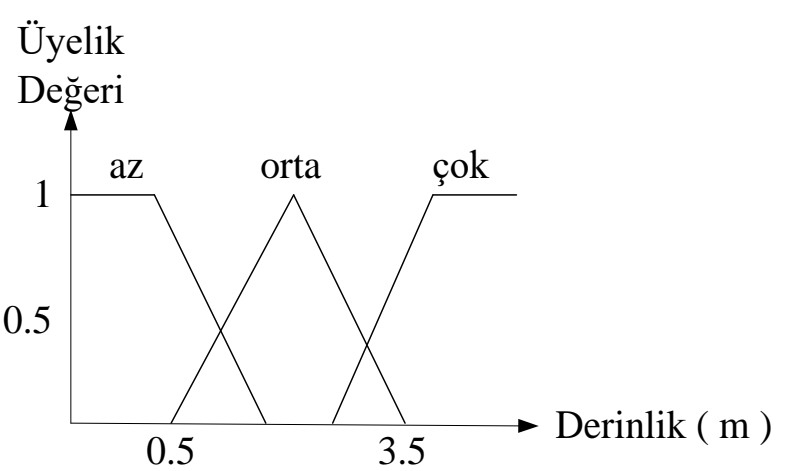

Şekil 4. Derinlik parametresinin üyelik fonksiyonları

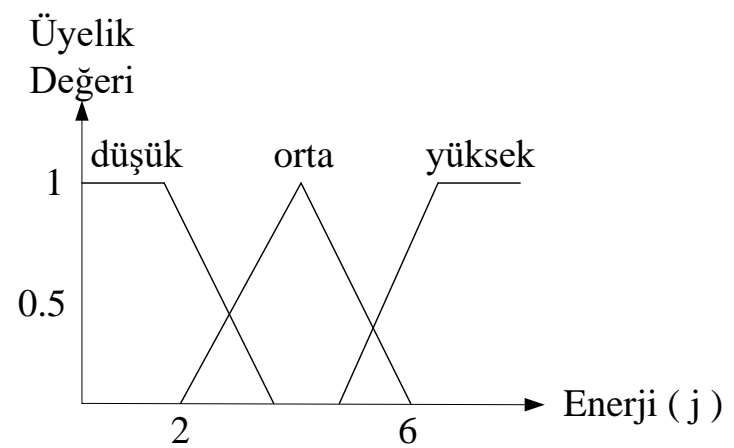

Şekil 5. Enerji parametresinin üyelik fonksiyonları

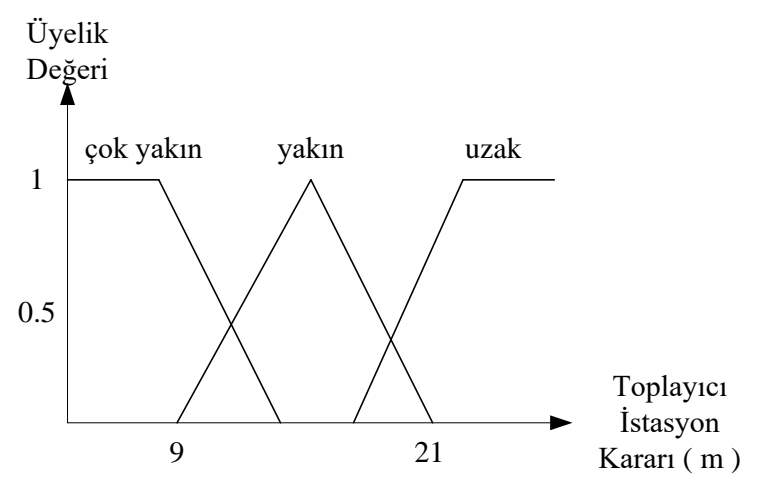

Şekil 6. Toplayıcı istasyon kararı üyelik fonksiyonları

Tablo 2. Bulanık mantık sisteminin kural tablosu

\begin{tabular}{|c|}
\hline Kurallar \\
\hline $\begin{array}{c}\text { Eğer (kullanım orta ise) ve (derinlik çok ise) ve (enerji düşük ise) o } \\
\text { zaman } \\
\text { (toplayıcı istasyon kararı çok yakın) olur }\end{array}$ \\
$\begin{array}{c}\text { Eğer (kullanım az ise) ve (derinlik az ise) ve (enerji düşük ise) o } \\
\text { zaman } \\
\text { (toplayıcı istasyon kararı yakın) olur }\end{array}$ \\
$\begin{array}{c}\text { Eğer (kullanım çok ise) ve (derinlik çok ise) ve (enerji yüksek ise) o } \\
\text { zaman } \\
\text { (toplayıcı istasyon kararı çok yakın) olur }\end{array}$ \\
\hline $\begin{array}{c}\text { Eğer (kullanım orta ise) ve (derinlik çok ise) ve (enerji orta ise) o } \\
\text { zaman } \\
\text { (toplayıcı istasyon kararı uzak) olur }\end{array}$ \\
\hline
\end{tabular}

Tablo 2. devam1

\begin{tabular}{|c|}
\hline Kurallar \\
\hline $\begin{array}{c}\text { Eğer (kullanım orta ise) ve (derinlik çok ise) ve (enerji yüksek ise) o } \\
\text { zaman } \\
\text { (toplayıcı istasyon kararı çok yakın) olur }\end{array}$ \\
\hline $\begin{array}{c}\text { Eğer (kullanım orta ise) ve (derinlik orta ise) ve (enerji yüksek ise) o } \\
\text { zaman } \\
\text { (toplayıcı istasyon kararı çok yakın) olur }\end{array}$ \\
\hline $\begin{array}{l}\text { Eğer (kullanım orta ise) ve (derinlik orta ise) ve (enerji orta ise) o } \\
\text { zaman } \\
\text { (toplayıcı istasyon kararı yakın) olur }\end{array}$ \\
\hline $\begin{array}{l}\text { Eğer (kullanım orta ise) ve (derinlik orta ise) ve (enerji düşük ise) o } \\
\text { zaman } \\
\text { (toplayıcı istasyon kararı uzak) olur }\end{array}$ \\
\hline $\begin{array}{l}\text { Eğer (kullanım orta ise) ve (derinlik az ise) ve (enerji yüksek ise) o } \\
\text { zaman } \\
\text { (toplayıcı istasyon kararı çok yakın) olur }\end{array}$ \\
\hline $\begin{array}{l}\text { Eğer (kullanım orta ise) ve (derinlik az ise) ve (enerji orta ise) o } \\
\text { zaman } \\
\text { (toplayıcı istasyon kararı uzak) olur }\end{array}$ \\
\hline $\begin{array}{c}\text { Eğer (kullanım orta ise) ve (derinlik az ise) ve (enerji düşük ise) o } \\
\text { zaman } \\
\text { (toplayıcı istasyon kararı çok yakın) olur }\end{array}$ \\
\hline $\begin{array}{l}\text { Eğer (kullanım az ise) ve (derinlik çok ise) ve (enerji düşük ise) o } \\
\text { zaman } \\
\text { (toplayıcı istasyon kararı yakın) olur }\end{array}$ \\
\hline $\begin{array}{l}\text { Eğer (kullanım az ise) ve (derinlik çok ise) ve (enerji orta ise) o } \\
\text { zaman } \\
\text { (toplayıcı istasyon kararı yakın) olur }\end{array}$ \\
\hline $\begin{array}{l}\text { Eğer (kullanım az ise) ve (derinlik çok ise) ve (enerji yüksek ise) o } \\
\text { zaman } \\
\text { (toplayıcı istasyon kararı yakın) olur }\end{array}$ \\
\hline $\begin{array}{l}\text { Eğer (kullanım az ise) ve (derinlik orta ise) ve (enerji yüksek ise) o } \\
\text { zaman } \\
\text { (toplayıcı istasyon kararı uzak) olur }\end{array}$ \\
\hline $\begin{array}{c}\text { Eğer (kullanım az ise) ve (derinlik orta ise) ve (enerji orta ise) o } \\
\text { zaman } \\
\text { (toplayıcı istasyon kararı çok yakın) olur }\end{array}$ \\
\hline $\begin{array}{l}\text { Eğer (kullanım az ise) ve (derinlik orta ise) ve (enerji düşük ise) o } \\
\text { zaman } \\
\text { (toplayıcı istasyon kararı çok yakın) olur }\end{array}$ \\
\hline $\begin{array}{l}\text { Eğer (kullanım az ise) ve (derinlik az ise) ve (enerji yüksek ise) o } \\
\text { zaman } \\
\text { (toplayıcı istasyon kararı yakın) olur }\end{array}$ \\
\hline $\begin{array}{c}\text { Eğer (kullanım az ise) ve (derinlik az ise) ve (enerji orta ise) o } \\
\text { zaman } \\
\text { (toplayıcı istasyon kararı yakın) olur }\end{array}$ \\
\hline $\begin{array}{c}\text { Eğer (kullanım çok ise) ve (derinlik çok ise) ve (enerji orta ise) o } \\
\text { zaman } \\
\text { (toplayıcı istasyon kararı çok yakın) olur }\end{array}$ \\
\hline $\begin{array}{l}\text { Eğer (kullanım çok ise) ve (derinlik çok ise) ve (enerji düşük ise) o } \\
\text { zaman } \\
\text { (toplayıcı istasyon kararı çok yakın) olur }\end{array}$ \\
\hline $\begin{array}{c}\text { Eğer (kullanım çok ise) ve (derinlik orta ise) ve (enerji yüksek ise) o } \\
\text { zaman } \\
\text { (toplayıcı istasyon kararı uzak) olur }\end{array}$ \\
\hline $\begin{array}{l}\text { Eğer (kullanım çok ise) ve (derinlik orta ise) ve (enerji orta ise) o } \\
\text { zaman } \\
\text { (toplayıcı istasyon kararı yakın) olur }\end{array}$ \\
\hline $\begin{array}{l}\text { Eğer (kullanım çok ise) ve (derinlik orta ise) ve (enerji düşük ise) o } \\
\text { zaman } \\
\text { (toplayıcı istasyon kararı uzak) olur }\end{array}$ \\
\hline $\begin{array}{c}\text { Eğer (kullanım çok ise) ve (derinlik az ise) ve (enerji yüksek ise) o } \\
\text { zaman } \\
\text { (toplayıcı istasyon kararı çok yakın) olur }\end{array}$ \\
\hline $\begin{array}{c}\text { Eğer (kullanım çok ise) ve (derinlik az ise) ve (enerji orta ise) o } \\
\text { zaman } \\
\text { (toplayıcı istasyon kararı yakın) olur }\end{array}$ \\
\hline $\begin{array}{c}\text { Eğer (kullanım çok ise) ve (derinlik az ise) ve (enerji düşük ise) o } \\
\text { zaman } \\
\text { (toplayıcı istasyon kararı yakın) olur }\end{array}$ \\
\hline
\end{tabular}




\section{Performans Analizi}

Şekil 7'de, toplayıcı istasyonların her biri için ortalama iş çıkarma başarımı sonuçları görülmektedir. Ortalama iş çıkarma başarımı $\% 80$ ile \%98 arasında değișiklik göstermektedir. Ortalama iş çıkarma başarımı, 2000 saniye sonunda tüm toplayıcı istasyonlar için \%10 oranında düşüş göstermektedir. Bunun nedeni, derinlikten dolayı enerjisi tükenen düğümlerin iletişimde kayıplara sebep olmasıdır. İletişimde yaşanan aksaklıklar veri paketlerinin teslim edilememesine ve ortalama iş çıkarma başarımının düşmesine yol açmaktadır.

Şekil 8'de, toplayıcı istasyonların her biri için derinliğe göre ortalama enerji tüketimi sonuçları görülmektedir. Enerji tüketimi 0 ile $6 \mathrm{~J}$ arasında değişmektedir. Ortalama enerji tüketimi, tüm toplayıcı istasyonlar için derinlikle yaklaşık olarak doğru orantılı bir şekilde artmaktadır. Bunun sebebi, derinlik arttıkça iletişimin zorlaşması ve daha çok enerji tüketimi gerektirmesidir.

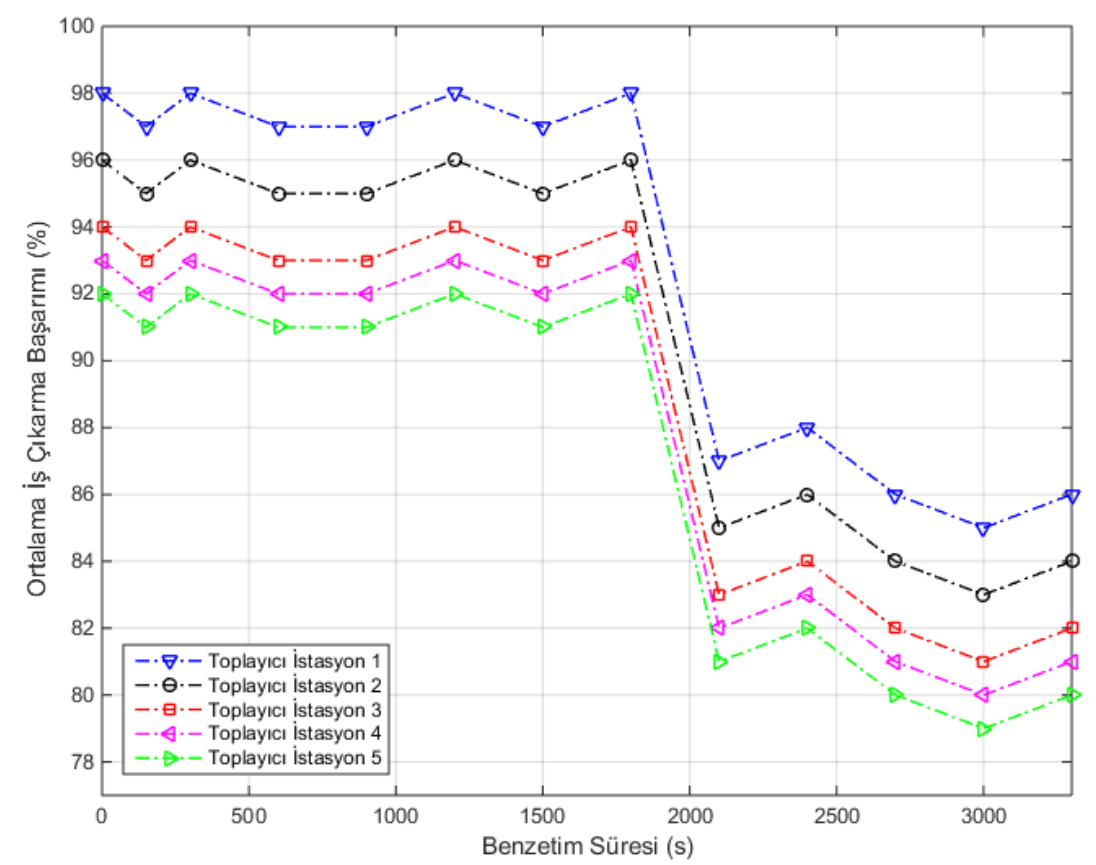

Şekil 7. Ortalama iş çıkarma başarımı

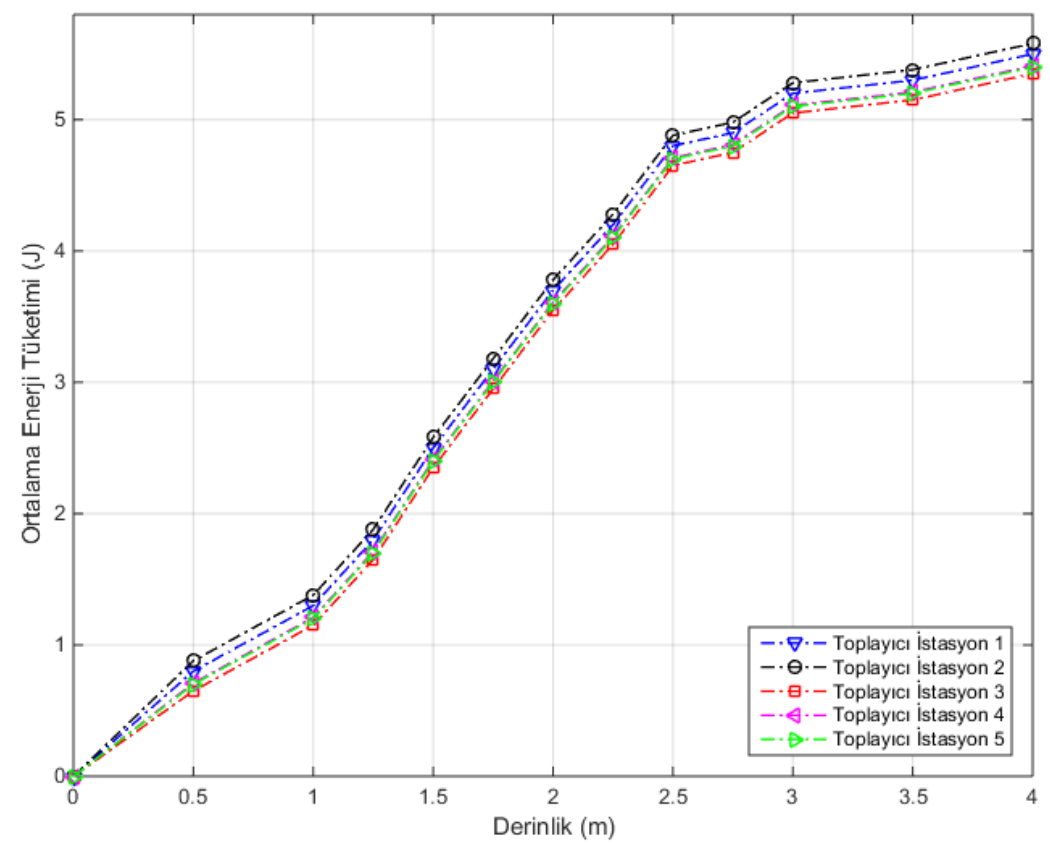

Şekil 8. Derinliğe göre ortalama enerji tüketimi 


\section{Bulgular ve Tartışma}

Bu çalışmada, yeraltı kablosuz algılayıcı ağlarında kayıpsız veri iletimi yapabilmesi için bulanık mantık tabanlı toplayıcı istasyon karar yaklaşımı önerilmiştir. Önerilen yeraltı kablosuz algılayıcı ağ yapısının benzetim modeli Riverbed yazılımı kullanılarak gerçekleştirilmiştir. Matlab yazılımı kullanılarak anlık olarak bulanık mantık tabanlı karar işlemi yapılmıștır. Yeraltı kablosuz algılayıcı a ğ performansını değerlendirmek için iş çıkarma başarımı ve enerji tüketimi parametreleri incelenmiştir. Performans değerlendirme sonuçları incelendiğinde; ortalama enerji tüketimi ile maksimum iş çıkarma başarım oranının yeraltı kablosuz algilayıcı ağlarda elde edilebileceği gösterilmiştir. $\mathrm{Bu}$ koşullar altında; en uygun toplayıcı istasyon seçimi yapılarak enerji tüketiminin mümkün olan en az seviyede tutulması sağlanmıştır.

Önerilen bulanık mantık tabanlı toplayıcı istasyon karar yaklaşımı sayesinde, en uygun toplayıcı istasyon seçimi yapılmıştır. Bulanık mantık kullanılmadan tasarlanan algılayıcı ağlarda, toplayıcı istasyon seçimi gelişigüzel bir şekilde yapılmaktadır. Rastgele yapılan toplayıcı istasyon seçimleri de enerji tüketimini artırmakta ve veri kayıplarından dolayı iş çıkarma başarımını önemli ölçüde düşürmektedir. $\mathrm{Bu}$ sebeple, rastgele toplayıc1 istasyon seçim işlemi tercih edilmemektedir. Önerilen bulanık mantık tabanlı sistemin $\% 90$ üzerinde ortalama iş çıkarma başarımı göstermesi, paket kayıplarının çok düşük oranda yaşandığını göstermektedir. Çok düşük paket kayıpları, önerilen algılayıcı ağ toplayıc1 istasyon seçim yaklaşımının istikrarlı olduğunu ortaya koymaktadır.

Yeraltı kablosuz algılayıcı ağlar, gün geçtikçe kullanım alanı artan bir konu haline gelmiştir. $\mathrm{Bu}$ kapsamda; yeraltı maden ocaklarından, tarımsal uygulamalara kadar çok geniş bir yelpazede kolaylıklar sağlayabilecek algılayıcı dügümler bulunmaktadır. Örneğin; tarımsal alanda toprak altındaki nem, sicaklık durumu, mineral tespiti vb. değerlerin sürekli olarak takip edilmesi elzemdir. Buna benzer alanlarda çalışmalar yaparak, enerji tüketimini verimli hale getirmek oldukça önemlidir.

\section{Teşekkür}

Değerli desteklerinden dolayı kıymetli Eşim Sümeyye ve kızım Asel'e çok teşekkür ederim.

\section{Kaynaklar}

Ahmad A H, Jaafar J, Mahmood A K, Agent-based personal monitoring system simulation using type-2 fuzzy, National Postgraduate Conference, 2011, Kuala Lumpur, pp. 1-5.

Alzoubi M A, Zueter A, Nie-Rouquette A, Sasmito A P, Freezing on demand: A new concept for mine safety and energy savings in wet underground mines. Int J Min Sci Technol 2019; 29(4): 621627.

Fischer D, Szabados B, Poehlman S, Combining neural networks, fuzzy logic, and Kalman filtering in an oil leak detector for underground electric power cables, Proceedings of the 21st IEEE Instrumentation and Measurement Technology Conference (IEEE Cat. No.04CH37510), 2004, Como, pp. 2099-2104.

Gauss V A, Bay J S, A fuzzy logic solution for navigation of an autonomous subsurface planetary exploration robot, Proceedings of the 1998 IEEE International Symposium on Intelligent Control (ISIC) held jointly with IEEE International Symposium on Computational Intelligence in Robotics and Automation (CIRA) Intell, 1998, Gaithersburg, MD, USA, pp. 559-564.

Gupta S, Kumar P, Karmakar N C, Palei S K, Quantification of human error rate in underground coal mines - A fuzzy mapping and rough set based approach, IEEE International Conference on Industrial Engineering and Engineering Management, 2013, Bangkok, pp. 140-144.

Huang Y R, Chen Z P, Han T, Liu X T, One energyefficient random-walk topology evolution method for underground wireless sensor networks. Int J Distrib Sens N 2018; 19(9): 1-9.

Ichihashi H, Katada T, Fujiyoshi M, Notsu A, Honda $\mathrm{K}$, Improvement in the performance of camera based vehicle detector for parking lot, International Conference on Fuzzy Systems, 2010, Barcelona, pp. 1-7.

Ichihashi H, Notsu A, Honda K, Katada T, Fujiyoshi M, Vacant parking space detector for outdoor parking lot by using surveillance camera and FCM classifier, IEEE International Conference on Fuzzy Systems, 2009, Jeju Island, pp. 127134.

Jaryani S, Broumandnia A, Oghani M A, Improving routing in wireless sensor networks having mobile sinks through fuzzy algorithm, 2nd International Conference on Knowledge-Based Engineering and Innovation (KBEI), 2015, Tehran, pp. 497-503. 
Lokshina I V, Insinga R C, Decision support system of ventilation operator based on fuzzy methods applied to interpretation and processing of gasdynamic images, SympoTIC'03, Joint 1st Workshop on Mobile Future and Symposium on Trends in Communications, 2003, Bratislava, Slovakia, pp. 84-89.

Ma F, Sensor networks-based monitoring and fuzzy information fusion System for underground Gas disaster, 9th International Conference on Fuzzy Systems and Knowledge Discovery, 2012, Sichuan, pp. 596-600.

Muduli L, Jana P K, Mishra D P, Wireless sensor network based fire monitoring in underground coal mines: A fuzzy logic approach. Process Saf Environ 2018; 113: 435-447.

Shahooei S, Mattingly S P, Shahandashti M, Ardekani $\mathrm{S}$, Propulsion system design and energy optimization for autonomous underground freight transportation systems. Tunn Undergr Sp Tech 2019; 89: 125-132.
Sinha S K, Karray F, Classification of underground pipe scanned images using feature extraction and neuro-fuzzy algorithm. IEEE Trans Neural Netw 2002; 13(2): 393-401.

Sinha S K, Karray F, Fieguth P W, Underground pipe cracks classification using image analysis and neuro-fuzzy algorithm, Proceedings of the IEEE International Symposium on Intelligent Control Intelligent Systems and Semiotics (Cat. No.99CH37014), 1999, Cambridge, MA, USA, pp. 399-404.

Xianmin M, Lan L, Monitoring System of Coal Electrical Haulage Shearer Based on Data Fusion Theory, International Symposium on Computer, Consumer and Control, 2014, Taichung, pp. 231-234.

Zyada Z, Kawai Y, Matsuno T, Fukuda T, Sensor Fusion Based Fuzzy Rules Learning for Humanitarian Mine Detection, SICE-ICASE International Joint Conference, 2006, Busan, pp. 1860-1865. 